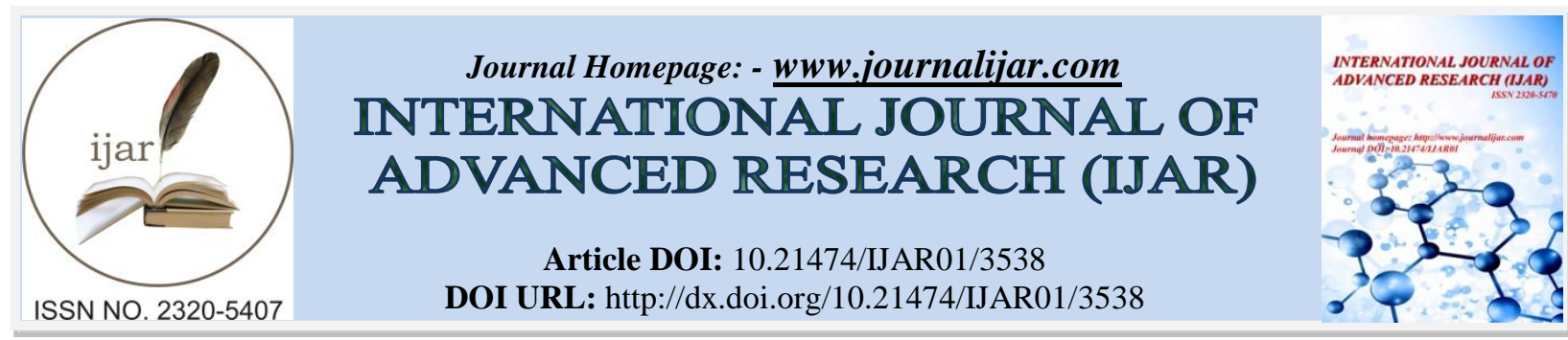

RESEARCH ARTICLE

\title{
SURVEY ON AWARENESS ABOUT ORTHODONTIC TREATMENT IN GENERAL POPULATION OF NAGPUR DISTRICT.
}

\section{Dr Atram Harish ${ }^{1}$, Dr Jakati Sanjeev V ${ }^{1}$, Dr Namrata Khetal ${ }^{2}$, Dr PV Hazarey ${ }^{3}$, Dr Mrunal Aley ${ }^{4}$, Dr Achint Chachada $^{4}$ and Dr Mugdha Mankar ${ }^{1}$.}

1. MDS Orthodontics, Assistant Professor Orthodontics \& Dentofacial Orthopaedics, Swargiya Dadasaheb Kalmegh Smruti Dental College \& Hospital Nagpur Maharashtra India.

2. BDS, Swargiya Dadasaheb Kalmegh Smruti Dental College \& Hospital Nagpur Maharashtra India.

3. MDS Orthodontics Professor \& HOD ,Orthodontics \& Dentofacial Orthopaedics, Swargiya Dadasaheb Kalmegh Smruti Dental College \& Hospital Nagpur Maharashtra India.

4. MDS Orthodontics Associate Professor, Orthodontics \& Dentofacial Orthopaedics, Swargiya Dadasaheb Kalmegh Smruti Dental College \& Hospital Nagpur Maharashtra India

\section{Manuscript Info}

Manuscript History

Received: 18 January 2017

Final Accepted: 20 February 2017

Published: March 2017

Key words:-

Malocclusion, Awareness, questionnaire survey.

\section{Abstract}

Context: Malocclusion is not a disease in itself but a variation in the arrangement of teeth, morphology of jaws, face and cranium. Awareness is the state or ability to perceive, to feel or to be conscious. Awareness forms the basis for planning oral health which is an inseparable part of general health.

Aims \& Objectives: - To assess the awareness of orthodontic problems $\&$ its treatment in Nagpur District.

Materials \& Methods: A cross sectional, observational (nonexperimental) descriptive questionnaire survey was conducted in urban population of Nagpur District. Two age groups were studied i.e. adolescence and adult. According to the prestructured questionnaire (15 objective questions) data was formulated for assessment of knowledge and awareness of orthodontic treatment.

Results: There were no statistically significant differences in general information and awareness about the proper age of orthodontic treatment.

Conclusion: Awareness of malocclusion and the need to make corrections has increasingly become prevalent among our population. As growing public interest in oral health increased, the demand for orthodontic treatment also became more noticeable in dental practices.

Copy Right, IJAR, 2017,. All rights reserved.

\section{Introduction:-}

Oral health can affect general health \& well being of childhood through development. Malocclusion is not a disease in itself but a variation in the arrangement of teeth, morphology of jaws, face and cranium. Desire and need for orthodontic treatment is influenced by awareness, socioeconomic factors, and availability of the experts, ethnic trends and values. Awareness is the state or ability to perceive, to feel or to be conscious. Awareness forms the basis for planning oral health which is an inseparable part of general health. With the availability of meristic criteria and

Corresponding Author:- Dr Jakati Sanjeev $\mathbf{V}^{\mathbf{1}}$.

Address:- Orthodontics \& Dentofacial Orthopaedics, Swargiya Dadasaheb Kalmegh Smruti Dental 
evolutions of indices of malocclusion, information on malocclusion and treatment needs is now being made available from all around the world.

\section{Aims \& Objectives:-}

There is a paucity of data about the awareness of orthodontic treatment among school children in the Indian context. Therefore the rationale for this study was to assess the awareness of children towards orthodontic problems \& its treatment. In this context, the objective of the present epidemiological survey was to assess the awareness of orthodontic problems \& its treatment in Nagpur District.

\section{Materials \& Methods:-}

A cross sectional, observational (non- experimental) descriptive questionnaire survey was conducted in urban population of Nagpur District. The sample size of 2000 people represented the rural population of Nagpur District. The sample was constituted from patients reporting to college OPD, patients from satellite clinics and students from school and college. In this modern era, though general population is aware of a dentist yet many people are unaware of Orthodontics as a speciality dealing with misalignment of teeth. Even if people are aware of orthodontics they hesitate to seek the treatment because of high cost of treatment, long duration of treatment, esthetic concern about placement of orthodontic appliance, extraction of some teeth if necessary. This survey has been formulated to evaluate the concern of general population in seeking orthodontic treatment.

Two age groups were studied i.e. adolescence and adult. People in age group 13-19 years constituted adolescent group \& and People in age group of 20-40 years constituted adult group. Children who obtained written informed consent from parents to participate in the study were included. Exclusion criteria used were- history of previous orthodontic treatment, rampant caries, multiple missing teeth, mutilated malocclusion and other craniofacial anomalies like cleft lip and palate, facial hemiatropy, cleidocranial dysplasia etc. An oral health lecture was given to all the children in the school to create awareness about Dental health and Orthodontic treatment.

Statistical data was analysed and categorised according to age and gender. Responses of the people were recorded on a 3 point Likert scale from poor, fair and good. According to the prestructured questionnaire (15 objective questions) data was formulated for assessment of knowledge and awareness of orthodontic treatment.

\section{Questions included were:-}

Q.1) Have you ever visited a dentist?
a) Yes
b) No

Q.2) Have you heard of an orthodontist?
a) Yes
b) No

Q.3) Are you aware that an Orthodontist can bring your teeth in proper position?
a) Yes
b) No

Q.4) Did you notice improper positioning of your teeth by yourself or was it told to you by society/others?
a) Yourself b) Society/others.

Q.5) Have you ever noticed people with improperly positioned teeth?
a) Yes
b) No

Q.6) Do you think that teeth should be properly positioned for a better facial appearance?
a) Yes
b) No

Q.7) Do you know at what age orthodontic treatment should be started?
a) At school
b) Junior college

Q.8) Do you know the side effects of improperly positioned teeth?
a) Yes
b) No

Q.9) Do you know that taking proper orthodontic treatment at an early age would improve your facial appearance?
a) Yes
b) No

Q.10) Do you know the cost of orthodontic treatments?
a) Yes
b) No

Q.11) Do you know how much time, orthodontic treatment takes?
a) $<1$ year
b) 2-3 year

Q.12) Are you aware that few teeth may have to be removed for proper positioning of irregular teeth?
a) Yes
b) No

Q.13) Do you know different types of habits that can cause improper positioning of teeth? 

a) Yes
b) No

Q.14) Do you know about orthodontic braces and its types?

a) Metallic Braces, Ceramic Braces

b) Lingual Braces , invisalign braces

Q.15) Are you aware that the improperly positioned teeth can be corrected at the age of 35-40 yrs also?
a) Yes
b) $\mathrm{No}$

Statistical analysis:-

Data was coded and entered into excel sheet. To maintain the data quality (validity) rechecking and cross checking was done during data entry phase. Later, data was transferred into SPSS windows version 16, where cleaning, coding, recording, crosschecking, processing and analysis of the data were done. Simple

Descriptive statistics was applied to describe the study variables. The t- test procedure was used to compare means for two groups.

\section{Results:-}

There were no statistically significant differences in general information and awareness about the proper age of orthodontic treatment. Gender \& Age distribution of the sample participating in the study is represented in Tables 1 and 2 .

Table 1:- Distribution of sample size

\begin{tabular}{|c|c|c|}
\hline Gender & Frequency & Percentage \\
\hline Female & 1010 & $50.5 \%$ \\
\hline Male & 990 & $49.5 \%$ \\
\hline Total & 2000 & $100 \%$ \\
\hline
\end{tabular}

Table 2:- Age wise distribution.

\begin{tabular}{|c|c|c|}
\hline Age & Frequency & Percentage \\
\hline $15-24$ & 650 & 32.5 \\
\hline $25-34$ & 800 & 40 \\
\hline $35-44$ & 440 & 22 \\
\hline $45-54$ & 110 & 5.5 \\
\hline Total & 2000 & 100 \\
\hline
\end{tabular}

Table 3:- Response to Q1 -Q6.

\begin{tabular}{|c|c|c|c|c|c|c|c|c|c|c|c|c|}
\hline & \multicolumn{2}{|c|}{ Q1 } & \multicolumn{2}{|c|}{ Q2 } & \multicolumn{2}{|c|}{ Q3 } & \multicolumn{2}{|c|}{ Q4 } & \multicolumn{2}{|c|}{ Q5 } & \multicolumn{2}{|c|}{ Q6 } \\
\hline & $\mathbf{a}$ & $\mathbf{b}$ & $\mathbf{a}$ & $\mathbf{b}$ & $\mathbf{a}$ & $\mathbf{b}$ & $\mathbf{a}$ & $\mathbf{b}$ & $\mathbf{a}$ & $\mathbf{b}$ & $\mathbf{a}$ & $\mathbf{b}$ \\
\hline Frequency & 550 & 1450 & 550 & 1450 & 660 & 1340 & 550 & 1450 & 700 & 1300 & 790 & 1210 \\
\hline Percent & 27.5 & 72.5 & 27.5 & 72.5 & 33 & 67 & 27.5 & 72.5 & 35 & 65 & 39.5 & 60.5 \\
\hline
\end{tabular}

Table 4:- Response to Q7 - Q12

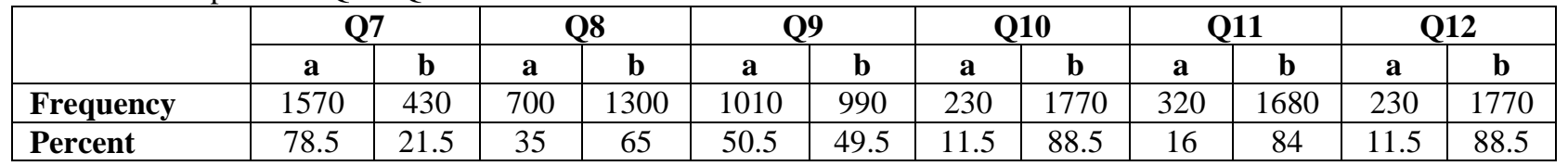

Table 5:- Response to Q13 - Q15.

\begin{tabular}{|l|c|c|c|c|c|c|}
\hline \multirow{2}{*}{ Frequency } & \multicolumn{2}{|c|}{ Q13 } & \multicolumn{2}{c|}{ Q14 } & \multicolumn{2}{c|}{ Q15 } \\
\cline { 2 - 7 } & $\mathbf{a}$ & $\mathbf{b}$ & $\mathbf{a}$ & $\mathbf{b}$ & $\mathbf{a}$ & $\mathbf{b}$ \\
\hline Percent & 1450 & 550 & 1210 & 790 & 700 & 1300 \\
\hline
\end{tabular}


Table 6:- Gender wise evaluation of response

\begin{tabular}{|c|c|c|c|c|}
\hline & \multicolumn{2}{|c|}{ GENDER } & \multirow{2}{*}{ Total } \\
\hline & & Female & Male & \\
\hline \multirow[t]{3}{*}{ Evaluation } & FAIR & 240 & 310 & 550 \\
\hline & GOOD & 640 & 580 & 1220 \\
\hline & POOR & 130 & 100 & 230 \\
\hline \multicolumn{2}{|c|}{ Total } & 1010 & 990 & 2000 \\
\hline
\end{tabular}

Chi Square $=1.55 \mathrm{p}=0.459$

Table 7:- Age wise evaluation of response.

\begin{tabular}{|c|c|c|c|c|c|c|}
\hline & \multicolumn{4}{|c|}{ AGE } & \multirow{2}{*}{ Total } \\
\hline & & $15-24$ & $25-34$ & $35-44$ & $45-54$ & \\
\hline \multirow[t]{3}{*}{ Evaluation } & GOOD & 370 & 500 & 240 & 110 & 1220 \\
\hline & POOR & 90 & 80 & 60 & 00 & 230 \\
\hline & FAIR & 190 & 220 & 140 & 00 & 550 \\
\hline \multicolumn{2}{|l|}{ Total } & 650 & 800 & 440 & 110 & 2000 \\
\hline
\end{tabular}

Chi Square $=8.55 \mathrm{p}=0.2$

According to their survey answers we found out that Majority of the sample included in this study had never visited a dentist before (Q1) neither the orthodontist (Q2) \& his area of specialization (Q3). These people were told about their mal-alignment of teeth by other people of the society (Q4) \& were not yet aware of the functioning of the orthodontist (Q6). These subjects were not aware of the side effects of improperly positioned teeth (Q8). They believed that this kind of treatment should be started at an early age (Q7) in order to improve their facial appearance (Q9), even though they were not aware about the cost of such treatment (Q10). They showed awareness that such treatment could take more than 2 years (Q11), but were not aware that few sound teeth had to be sacrificed for the same (Q12). The survey revealed that they had a knowledge about various habits causing malocclusion (Q13), metallic \& teeth colored ceramic braces (Q14) but were not about adult orthodontic treatments (Q15). (Table 3-7)

\section{Discussion:-}

"Why people do not seek orthodontic treatment?" is the driving question among all staring orthodontist \& a driving force for this study. The answer to this question would wary from, "Lack of Awareness, Metal display, Expensive treatment, Duration of treatment or Extraction of sound teeth". The exact satisfactory response to this question was evaluated through this study.

Globally, there has been an increase in awareness of Orthodontics as a dental specialty in children as well as adults [1-2]. The level of dental health knowledge, positive dental health attitude, and dental health behavior are interlinked

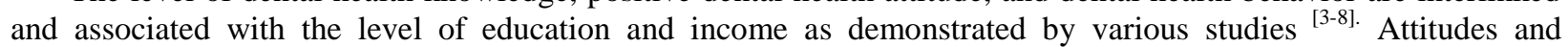
perceptions towards dental appearance differ among populations and among individuals ${ }^{[9,10]}$.

Self-awareness is a dynamic process, not a static phenomenon ${ }^{[11]}$. Although; imparting oral health education begins from the footstep of awareness, evaluation of its implementation is an important indicator of the success of the education imparted ${ }^{[12]}$. Age-related changes in malocclusion concerns ideally should be studied longitudinally because with the progress in age, the awareness to nature \& complexity of malocclusion increases.

In a similar study by Siddegowda ${ }^{13}$, High school children showed a higher level of awareness about orthodontic treatment when compared to middle school children. Urban children had shown more positive attitude like visiting a dentist in a study done by Singh et al. in $2012^{[14]}$ Considering the influence of age on awareness of orthodontics, it was found that it increased significantly. Similar findings were seen in a study conducted by Friedman et al., in $1976^{[14]}$ The aim of orthodontic procedure is to improve dental occlusion, which results in better smile and good functioning in harmony with the face ${ }^{[13]}$ Overall, it has been seen as an increase in awareness of orthodontic treatments as a dental specialty among children as well as adults. ${ }^{[1]}$

\section{Conclusion:-}

Enhancing appearance and improving psychosocial status have been identified as important motivating factors behind the decision to initiate orthodontic treatment. This survey created awareness of orthodontic treatment among 
various patients \& children's. Awareness of malocclusion and the need to make corrections has increasingly become prevalent among our population. As growing public interest in oral health increased, the demand for orthodontic treatment also became more noticeable in dental practices.

\section{References:-}

1. Anitha G, Asiya B. Adult Orthodontics IJDA,2010; 2: 96-99

2. Dacosta ON; The prevalence of malocclusion among a population of northern Nigerian school children. West African J Med,1999; 18: 91-96.

3. Al-Wahadni A M, Al-Omiri MK, Kawamura M; Differences in self-reported oral health behavior between dental students and dental technology/dental hygiene students in Jordan. J Oral Sciences 2004; 46:191-7.

4. Kawamura M, Iwamoto Y, Wright FA; A comparison of self-reported dental health attitudes and behavior between selected Japanese and Australian students. J Dent Education, 1997; 61:354- 60.

5. Barrieshi-Nusair K, Alomari Q, Said K; Dental health attitudes and behavior among dental students in Jordan. Community Dent Health, 2006; 23:147- 51.

6. Kawamura M, Spadafora A, Kim KJ, Komabayashi T; Comparison of United States and Korean dental hygiene students using hiroshima university-dental behavioral inventory (HU-DBI). Int Dent, J 2002; 52:156-62.

7. Hamilton ME, Coulby WM; Oral health knowledge and habits of senior elementary school students. J Public Health Dent, 1991; 51: 212-9.

8. Kerosuo H , Laine T, Kerosuo E, Ngassapa D , Honkala E; Occlusion among a group of Tanzanian urban schoolchildren . Community Dentistry and Oral Epidemiology, 1988; $16: 306$ - 309

9. Nobile CG, Pavia M, Fortunato L, Angelillo IF; Prevalence and factors related to malocclusion and orthodontic treatment need in children and adolescents in Italy . European Journal of Public Health, 2007; 17:637 - 641.

10. Vallittu PK, Vallittu AS, Lassila VP (1996) Dental aesthetics--a survey of attitudes in different groups of patients. J Dent 24: 335-338.

11. Rochat P1 (2003) Five levels of self-awareness as they unfold early in life. Conscious Cogn 12: 717-731.

12. Navneet Grewal, Manpreet Kaur (2007) Status of oral health awareness in Indian children as compared to Western children: A thought provoking situation (A pilot study). Journal of Indian Society of Pedodontics and Preventive Dentistry 25:15-19.

13. Siddegowda R (2015) An Epidemiological Survey on the Awareness towards Orthodontic Treatment among Middle School and High School Children of Karnataka State. J Cell Sci Ther 6: 213

14. Singh K, Kochhar S, Mittal V, Agrawal A, Chaudhary H, Anandani C. Oral health: knowledge, attitude and behaviour among Indian population. Educ Res. 2012;3:066-71.

15. Friedman LA, Mackler IG, Hoggard GJ, French CI. A comparison of perceived and actual dental needs of a select group of children in Texas. Community Dent Oral Epidemiol. 1976;4:89-93. 